\title{
Reinterpretação da estrutura teórico-conceitual do conhecimento pedagógico do conteúdo
}

CDD. 20.ed. 371.12

\section{Resumo}

0 conhecimento pedagógico do conteúdo integra a base de conhecimentos para o ensino - conjunto de conhecimentos necessários ao professor - juntamente com aqueles relativos às características dos alunos, aos conteúdos da matéria de ensino, à pedagogia geral e aos contextos que circundam a aprendizagem. Considerando sua importância na formação inicial de professores, o objetivo deste ensaio foi o de analisar a estrutura da base de conhecimentos dos futuros professores de Educação Física sob a perspectiva do conhecimento pedagógico do conteúdo, buscando contribuir com o debate a respeito do papel desse conhecimento no planejamento e na implementação das situações de ensino e aprendizagem, bem como na formação docente dos estudantes-professores. Diante do referencial teórico analisado, pode-se compreender o conhecimento pedagógico do conteúdo como aquele que o estudante-professor utiliza para, a partir dos seus objetivos, da realidade dos alunos e das características do contexto de ensino e aprendizagem, convocar, gerir e fazer interagir os conhecimentos da base de conhecimentos para o ensino, visando à adaptação, à transformação e à implementação do conhecimento do conteúdo a ser ensinado, de modo a torná-lo compreensível e ensinável aos alunos. Para alcançar esses objetivos, a literatura sugere a aproximação do contexto de formação inicial em Educação Física daquele de atuação profissional do professor na Educação Básica, além da ampliação das oportunidades para que os estudantes-professores se defrontem com diferentes dilemas e situações-problema ao longo da formação inicial. Tais estratégias fomentarão a construção do conhecimento pedagógico do conteúdo e, consequentemente, o delineamento da personalidade docente dos futuros professores.

UnItermos: Formação de professores; Docência; Preparação docente; Base de conhecimentos.

\section{Introdução}

Análises e proposições relativas ao conjunto de conhecimentos, saberes, habilidades e competências, necessário para a docência, não são originais. Ao longo dos anos, diferentes autores (ENNIS, 1994; Grossman, 1990; Hegarty, 2000; Mizukami, 2004; Shulman, 1986, 1987; WoOds, Goc Karp \& EsCAMILLA, 2000) investiram esforços no sentido de ampliar os horizontes de reflexão sobre essa temática.

Apesar da diversidade de abordagens e do avanço nas pesquisas sobre o assunto, GRAÇA (1997) adverte, em seus estudos sobre o processo de formação inicial em Educação Física, que "a investigação sobre o ensino e a formação de professores" ainda "não é capaz de dar uma resposta indiscutível [...] a uma pergunta aparentemente tão inócua" como: "o que é que o professor necessita de saber?” (p.38-9).
A relevância do tema para o campo de estudo da docência, ao mesmo tempo que tem balizado a investigação nessa área, também ressalta a necessidade de se elucidar quais são e, principalmente, como os futuros professores de Educação Física gerem seus próprios conhecimentos para promover a aprendizagem dos alunos.

A proposta da base de conhecimentos para o ensino tem contribuído para isso. Amplamente reconhecida pela literatura (Cochran, King \& Deruiter, 1991; Graça, 1997; Grossman, 1990; Grossman, Wilson \& Shulman, 1989; Shulman, 1987), ela compreende o conjunto de conhecimentos necessários à atuação docente em distintos contextos de ensino e aprendizagem, no sentido de alcançar os objetivos relacionados à aprendizagem e à formação dos alunos. 
Conforme propuseram CoCHran, KING e DerUiTER (1991), a partir das formulações de SHULMaN (1987) e de Grossman (1990), dito conjunto inclui conhecimentos das características dos alunos, dos conteúdos da matéria de ensino, da pedagogia geral e dos contextos que circundam a aprendizagem, acrescidos de uma compreensão integrada e integradora dessas quatro componentes, o conhecimento pedagógico do conteúdo.

Essa descrição traz em cena o conhecimento pedagógico do conteúdo, e lhe confere participação destacada dentro da base de conhecimentos e nas práticas pedagógicas dos futuros professores. Essas questôes justificam o interesse em analisar tanto as funções assumidas pelo conhecimento pedagógico do conteúdo nas situações de ensino e aprendizagem quanto a maneira como ele interage com os demais integrantes da base de conhecimentos. Para tanto, e de modo a nortear o presente ensaio, foram estruturados dois diferentes, mas complementares, objetivos.

Primeiramente, se pretende analisar a maneira pela qual os outros quatro integrantes da base influenciam no processo de construção do conhecimento pedagógico do conteúdo, além de lançar luz sobre as funçôes, os objetivos e o papel assumido pelo conhecimento pedagógico do conteúdo dentro da base no sentido de viabilizar a aprendizagem dos alunos.

A partir disso, e como segundo objetivo, se busca a formulação de uma proposta de reinterpretação da estrutura teórico-conceitual do constructo do conhecimento pedagógico do conteúdo, no intuito de contribuir com a investigação concernente à formação inicial e com os próprios programas de formação inicial de professores de Educação Física.

\section{Base de conhecimentos para o ensino}

Os estudos que seguem a linha de pensamento de SHulman (1987) e que também adotam a expressão base de conhecimentos para o ensino, apresentam posicionamentos diversificados sobre a mesma problemática, como se cada um estivesse olhando por uma janela diferente para dentro do mesmo ambiente onde convivem os vários conhecimentos aos quais o professor recorre na sua atuação docente. De maneira geral, e com o respaldo das reflexões de KIND (2009), é possível identificar, na literatura, três abordagens, ou janelas, principais.

Uma delas se apoia na própria proposta de SHULMAN (1987), com a base de conhecimentos constituída por sete diferentes integrantes, relativamente, aos conhecimentos do conteúdo; pedagógico geral; do currículo; dos alunos e suas características; do contexto educacional; dos fins, propósitos e valores educacionais; e pedagógico do conteúdo. Além de fortemente aceita no campo dos estudos relacionados aos conhecimentos do professor, essa proposta passou a ser adotada, dentre outros, por autores como DarLING-HAMmOND (2006), GESS-NEWSOME (1999), Grossman (1990), Fenstermacher (1994), MizuKami (2004) e VAn Driel, Verloop e De Vos (1998).

Outra abordagem segue o pensamento de GrosSMAN (1990) que, derivada da proposta de SHULMAN (1987), interpreta a base de conhecimentos com quatro integrantes, nomeadamente os conhecimentos do conteúdo; pedagógico geral; do contexto; e pedagógico do conteúdo. Com essa proposta, a autora abriu uma nova janela pela qual autores como
Cochran, King e Deruiter (1991), Graça (1997), Park e Oliver (2008) e Ramos, GraçA e NascimenTO (2008) também passaram a observar e analisar o conjunto de conhecimentos necessários para o ensino.

A terceira janela, aberta por Cochran, King e DerUiter (1991), origina-se da mescla das propostas de Shulman (1987) e de Grossman (1990) e identifica os conhecimentos dos alunos; do conteúdo; pedagógico geral; do contexto; e pedagógico do conteúdo como os cinco integrantes da base de conhecimentos para o ensino. São exemplos de estudos que adotam essa perspectiva da base aqueles realizados por KIND (2009), por Veal e MaKinster (1999) e por MARCON (2011).

Independentemente da orientação teórica, da organização estrutural e do viés interpretativo desse conjunto de conhecimentos, o mais importante para o processo de formação inicial em Educação Física e para a atuação docente dos professores é o reconhecimento do papel da base, ou seja, o de congregar todos os conhecimentos necessários para a docência, os quais serão requisitados em diferentes instâncias da prática pedagógica dos futuros professores.

A base de conhecimentos se refere, pois, a um corpo de conhecimentos, concepçôes e disposições construídas em diferentes momentos, em distintos contextos e por meio de diversas vivências do estudanteprofessor, ao longo das trajetórias pessoal, escolar, acadêmica e profissional (SHULMAN, 1987; TARDIF \& RAYMOND, 2000). São justamente esses conhecimentos, concepções e disposiçōes que dão forma à base de 
conhecimentos do futuro professor de Educação Física e, além de serem requeridos para o ensino, também influenciam e determinam a maneira como desempenha suas funções e encaminha a aprendizagem dos seus alunos nas situações de ensino e aprendizagem (Marcon, Graça \& Nascimento, 2010).

As proposições de vários autores (BEHETS \& VERGAUWEN, 2006; DARIDO, 1995; FigUEIREDO, 2004; Garcia, 2001; GraÇA, 2001; Lima \& REALi, 2002; Marcelo, 1998; Marcon, GraÇa \& Nascimento, 2010; Meirieu, 2002; Shulman, 1987; Silva, 2008; TARDIF \& RAYMOND, 2000) sugerem que, ao ingressarem no Ensino Superior, os estudantes-professores levam consigo, na forma de lembranças, de sentimentos e de experiências, todas as suas impressões, informações, conhecimentos e concepçóes sobre a disciplina de Educação Física, a escola, a profissão de professor e o processo de ensino e aprendizagem. Esses elementos têm potencial para arquitetar a estrutura inicial da base de conhecimentos dos futuros professores e para apontar possíveis caminhos a serem seguidos por eles, seja na estruturação de suas novas concepções, seja nas suas escolhas e decisóes metodológicas em diferentes situaçóes de ensino e aprendizagem.

A base de conhecimentos para o ensino pode ser interpretada, portanto, como a responsável por envolver "conhecimentos de diferentes naturezas, todos necessários e indispensáveis para a atuação" do futuro professor (MizuKAMI, 2004, p.4), os quais definem a individualidade de cada estudante-professor, suas concepções e seus conhecimentos. Ao analisar essas questões na formação inicial em Educação Física, AMADE-Escot (2000) afirma, inclusive, que o próprio conhecimento pedagógico do conteúdo é "integrado por diferentes formas de conhecimentos, crenças e valores, todos os quais são essenciais para o desenvolvimento da experiência profissional" (p.80, tradução nossa).

Diante disso, as reflexóes realizadas a seguir, sobre a estrutura da base de conhecimentos dos futuros professores de Educação Física e sobre o papel do conhecimento pedagógico do conteúdo dentro da base, adotam como lastro teórico as abordagens de SHULMAN (1987) e de Grossman (1990), bem como o modelo de Cochran, KInG e DerUiter (1991), cujos integrantes são, justamente, os conhecimentos dos alunos; do conteúdo; pedagógico geral; do contexto; e pedagógico do conteúdo.

\section{Conhecimento dos alunos}

Na proposta de SHULMan (1987), o conhecimento dos alunos aparece diluído no conhecimento do contexto e diz respeito às particularidades sociais, culturais e psicológicas dos alunos em diferentes idades. No esquema de conhecimento profissional para o ensino, apresentado por GROSSMAN (1990), o conhecimento dos alunos surge não apenas no âmbito do conhecimento do contexto, mas também especificado como subcategoria do conhecimento pedagógico do conteúdo. Nesse caso, para ser usado nas práticas pedagógicas em sala de aula, o conhecimento dos alunos necessita ser adaptado à especificidade da situação de ensino e aprendizagem, ou seja, aos interesses e às necessidades dos alunos, bem como às demandas da área de matéria (GRAÇA, 1997, 2001; Grossman, 1990, 2008; Park, Jang, Chen \& Jung, 2010; Park \& Oliver, 2008; Ramos, GraÇA \& Nascimento, 2008; Rovegno \& Dolly, 2006).

Para além de assimilarem os pontos de vista de Shulman (1987) e de Grossman (1990), autores como Cochran, King e Deruiter (1991), Graber (1995), Intrator (2006), Levin, Hammer e Coffey (2009), O’ Sullivan e Doutis (1994), Rink (1997), Rovegno (1994, 1995, 2008), Rovegno e Dolly (2006), SchinCariol (2002), Whipple (2002), entre outros, acrescentam a participação dos aspectos sociais, políticos, culturais e físicos na maneira como cada aluno aprende, dando, assim, maior relevo ao conhecimento dos alunos, ao considerá-lo (autonomamente) como um dos pilares da base de conhecimentos.

Apesar de não ter aprofundado suas reflexões no que concerne ao conhecimento dos alunos, SHULmaN (1987) demonstra preocupação com as concepções e pré-concepções que diferentes alunos, com distintas idades, gêneros, conhecimentos, habilidades e experiências prévias trazem para a situação de ensino e aprendizagem, principalmente se elas constituírem concepções equivocadas. Nessa perspectiva, é salientada a necessidade de se atentar tanto para a forma como o futuro professor lida com essa diversidade de concepções e de pré-concepções quanto para as estratégias implementadas por ele na situação de ensino e aprendizagem, no sentido de ajudar a reorganizar a interpretação e a compreensão dos alunos e encaminhar a reconstrução de seus conhecimentos sobre o assunto (CHEN, 2004; DARLING-HAMMOND, 2006; FENSTERMACHER, 1994; GESS-NEWSOME, 1999; GraçA, 1997, 2001; Mizukami, 2004; Rovegno \& Dolly, 2006; Shulman, 1987). Do mesmo modo, e para que se alcancem objetivos relacionados à motivação e ao interesse, a literatura consultada (GréHaigne \& Godbout, 1995; MesQuita \& GraÇA, 2002; Mesquita, GraÇa, Gomes \& Cruz, 2005; Pereira, Mesquita \& Graça, 2010; Schincariol, 2002; Souza \& Oslin, 2008) preconiza que 
os professores de Educação Física valorizem a participação e a autonomia dos alunos nas inúmeras decisões tomadas no ambiente da sala de aula.

Por essas razões, é possível reconhecer que a estruturação e o gradativo aperfeiçoamento do conhecimento dos alunos proporcionem ao estudanteprofessor algumas das condiçôes necessárias para avançar consistentemente, durante a sua formação inicial, na construção e no desenvolvimento daquele que é considerado o componente nuclear do conhecimento para a docência: o conhecimento pedagógico do conteúdo (Amade-Escot, 2000; Cochran, King \& Deruiter, 1991; GraÇA, 1997, 2001; MizUKami, 2004; Segall, 2004; Shulman, 1987). Esse cenário explicita a importância do conhecimento dos alunos dentro da base de conhecimentos e sua relevância para a construção do conhecimento pedagógico do conteúdo e a formação docente e profissional dos futuros professores de Educação Física.

\section{Conhecimento do conteúdo}

O conhecimento do conteúdo se relaciona diretamente com a matéria a ser ensinada e é considerado um dos conhecimentos fundamentais para o sucesso da atuação docente, seja na área de Educação Física, seja na área das demais disciplinas curriculares. Ao mesmo tempo que o pleno domínio do conteúdo específico amplia as possibilidades de intervenção docente, sua deficiência restringe os caminhos pelos quais os estudantes-professores podem seguir para seu ensino aos alunos (AMADE-EsCOT, 2000; Arvazo, Ward \& STuHr, 2010; Calderhead, 1988; GrosSman, Wilson \& Shulman, 1989; Schempp, ManroOss, TAN \& Fincher, 1998; SChINCARIOl, 2002; Segall, 2004; Siedentop, 2002a; Tinning, 2002).

Ao analisar os estudos de Shulman, Mizukami (2004) subdivide o conhecimento do conteúdo em duas categorias, que dizem respeito aos momentos em que o estudante-professor aprende e aos momentos em que o estudante-professor ensina.

No primeiro caso, o estudante-professor necessita saber como o conhecimento se constrói e se estrutura, onde está embasado e como se sustenta perante as demais áreas. Ao aprender a respeito do conteúdo específico, espera-se que o futuro professor supere a mera compreensão dos conceitos da disciplina e se aprofunde na sua essência e nas suas origens (DARLING-HAMMOND, 2006; Grossman, Wilson \& Shulman, 1989; Segall, 2004; SiEDENTOP, 2002a; SMITH, 1997).

No segundo caso, nos momentos em que o estudante-professor ensina, espera-se a aquisição de um nível de conhecimento da matéria que lhe permita ampliar as possibilidades de representação pessoal sobre o assunto. Com isso, o estudante-professor passará a compreender o conteúdo de diferentes maneiras e sob diferentes ângulos, e, em função de seus objetivos e do nível de conhecimento dos seus alunos, o tornará útil e aplicável em diferentes situações de ensino e aprendizagem, viabilizando seu ensino (AYvAZO, WARD \& StUHr, 2010; MizUKami, 2004; SCHINCARIOL, 2002; Segall, 2004; Siedentop, 2002a).

Apesar de utilizarem diferentes denominações, esse ponto de vista é compartilhado por autoras como Altet (2001) e Rios (2002). Segundo elas, alguns dos saberes necessários ao professor dizem respeito aos saberes a ensinar (Rios, 2002) ou aos saberes a serem ensinados (ALTET, 2001), que são "construídos pelas ciências e tornados didáticos a fim de permitir aos alunos a aquisição de saberes constituídos e exteriores" (Altet, 2001, p.29); e aos saberes para ensinar (Altet, 2001; Rios, 2002), que incluem os saberes didáticopedagógicos e culturais sobre o que se está ensinando.

Sendo assim, pode-se admitir a existência de duas facetas distintas do conhecimento do conteúdo: o conhecimento do conteúdo a ser ensinado, que, oriundo dos momentos em que o estudante-professor aprende (Mizukami, 2004), dos saberes a ensinar (Rios, 2002) e dos saberes a serem ensinados (ALTET, 2001), representa o próprio objeto de ensino de determinado assunto para os alunos; e o conhecimento do conteúdo para ensinar, que, derivado dos momentos em que o estudanteprofessor ensina (Mizukami, 2004) e dos saberes para ensinar (ALTET, 2001; Rios, 2002), configura as suas concepçôes sobre as maneiras pelas quais determinado assunto pode ser ensinado aos alunos.

A consideração dessas duas facetas do conhecimento do conteúdo, de acordo com Schempr et al. (1998), permite aos estudantes-professores de Educação Física: a) aprimorar sua análise para reconhecer problemas e dificuldades de seus alunos; b) estruturar planejamentos que estejam em sintonia com a realidade dos seus alunos; c) ampliar seu repertório de estratégias de ensino e aprendizagem; e d) gerir suas aulas de maneira interativa, "confortável" e com mais entusiasmo (AMADE-Escot, 2000, p.82, tradução nossa).

Percebe-se, pois, que a literatura consultada (ALteT, 2001; AMAde-Escot, 2000; Ayvazo, Ward \& STUHR, 2010; CALDERHEAd, 1988; Graber, 1995; Grossman, Wilson \& Shulman, 1989; Mizukami, 2004; Pereira, MesQuita \& GRAÇA, 2010; Rios, 2002; SCHEMPP et al., 1998; SCHINCARIOL, 2002; SHULMAN, 1987; SieDENTOP, 2002a; Tinning, 2002; Veal \& Makinster, 1999) 
atribui grande responsabilidade ao conteúdo da matéria de ensino, independentemente de ser para ensinar ou a ser ensinado, uma vez que o considera um dos conhecimentos relevantes para as práticas pedagógicas ministradas pelos estudantes-professores.

Assim, o conhecimento do conteúdo assume elevada importância na formação inicial dos futuros professores de Educação Física, tornando-se um "pré ou correquisito" (MARKS, 1991, p.12, tradução nossa) imprescindível para o desenvolvimento adequado do conhecimento pedagógico do conteúdo, já que é dele que derivará o próprio conteúdo a ser ensinado aos alunos (Ayvazo, Ward \& STUHR, 2010; Graber, 1995; GraÇa, 1997; Schincariol, 2002; SHULman, 1987; Tinning, 2002; Veal \& MaKinster, 1999). Conforme enfatiza SiEDENTOP (2002a), mesmo que o conteúdo da matéria de ensino não seja claramente identificável na área de Educação Física, "você não pode ter conhecimento pedagógico do conteúdo sem conhecimento do conteúdo" (p.368, tradução nossa).

Em linha com esses autores e, ao reconhecerem a relevância do conhecimento do conteúdo no âmbito das atividades esportivas e no âmbito da construção do conhecimento pedagógico do conteúdo, Pereira, Mesquita e GraçA (2010) ressaltam que, sem ele, os futuros professores de Educação Física estarão sujeitos a uma inadequada adaptação aos fatores contextuais do processo de ensino. De fato, em traços gerais, a investigação aponta para a interferência do conhecimento da matéria de ensino na seleção, ordenação, sequencialização e grau de desenvolvimento dos conteúdos [...] e quantidade de questôes colocadas aos praticantes (p.151).

Apesar de sua destacada importância para a formação docente dos futuros professores, é fundamental considerar que, "embora o conhecimento do conteúdo específico seja necessário ao ensino, o domínio de tal conhecimento, por si só, não garante que [...] seja ensinado e aprendido com sucesso. É necessário, mas não suficiente" (MizUKAMI, 2004, p.5).

Em outras palavras, o conhecimento do conteúdo a ser ensinado somente se tornará ensinável quando for gerido, adaptado e transformado à luz dos conhecimentos do conteúdo para ensinar; dos alunos; pedagógico geral; do contexto; e pedagógico do conteúdo, todos esses que constituem, por essa razão, exemplos de conhecimentos para ensinar, e não, de conhecimentos a serem ensinados.

Em síntese, os programas de formação inicial em Educação Física necessitam desenvolver, nos estudantes-professores, os conhecimentos específicos relacionados à matéria de ensino e os conhecimentos necessários para fazer com que seus alunos compreendam essa matéria.

Admite-se, assim, que a estruturação e o gradativo aperfeiçoamento de ambas as facetas do conhecimento do conteúdo também ofereçam ao estudante-professor algumas das condições necessárias para encaminhar, durante a sua formação inicial, a construção e o desenvolvimento do seu conhecimento pedagógico do conteúdo (Amade-Escot, 2000; Cochran, KIng \& Deruiter, 1991; GraÇA, 1997, 2001; MizUKami, 2004; Segall, 2004; Shulman, 1987). Essas questōes também evidenciam a importância do conhecimento do conteúdo dentro da base de conhecimentos e sua relevância para a estruturação do conhecimento pedagógico do conteúdo e a formação docente e profissional dos futuros professores de Educação Física.

\section{Conhecimento pedagógico geral}

No que respeita à interpretação da literatura especificamente sobre o conhecimento pedagógico geral, é possível identificar posicionamentos que, apesar de origens distintas, comungam de princípios comuns e convergem para uma abordagem que, além de semelhante, é também peculiar.

A literatura consultada (AMADE-EsCot, 2000; Behets \& Vergauwen, 2006; Grossman, 2008; MetZler, TJeErdsma \& Mozen, 2000; MizuKami, 2004; Morine-Dershimer \& Kent, 1999; O'Sullivan \& DoutTs, 1994; RinK, 1997; Rovegno, 2008; SCHINCARIOL, 2002; SeEL, 1999; WhIPple, 2002) revela que, dentre os integrantes da base de conhecimentos, o conhecimento pedagógico geral é aquele por meio do qual o estudante-professor tanto manifesta suas concepções docentes e seus princípios educacionais quanto utiliza suas estratégias pedagógicas, planejando, organizando e gerindo as situações de ensino e aprendizagem de modo a superar o simples domínio do conhecimento do conteúdo e a alcançar objetivos mais amplos relacionados à educação e à formação dos alunos.

$\mathrm{Na}$ releitura da proposta original de SHULman (1987), Grossman (1990) aventou que o conhecimento pedagógico geral é responsável por congregar "um corpo de conhecimentos, crenças e habilidades gerais relacionadas ao ensino", dentre as quais se sobressaem os conhecimentos relativos aos alunos, ao currículo e à instrução, além de uma vertente adicional, denominada "gestão da sala de aula" (p.5-6, tradução nossa).

Percurso semelhante parece seguir MizUKAMI (2004), pois, ao analisar a proposta de SHULman (1987), se refere ao conhecimento pedagógico geral como um conhecimento que, além de transcender uma área 
específica, também engloba outros diferentes tipos de conhecimentos. Pelo que deixa transparecer, a autora, seguindo na esteira de Grossman (1990), também traz para o bojo do conhecimento pedagógico geral os conhecimentos do currículo e dos alunos, além dos conhecimentos do contexto educacional e dos fins, propósitos e valores educacionais, todos os quais, originalmente, situam-se na própria base de conhecimentos de SHULMAN (1987) (MizUKAMI, 2004).

O posicionamento de Grossman (1990) e de MizUKAMI (2004), particularmente sobre os conhecimentos do currículo e da gestão da sala de aula, guarda semelhanças com as análises de AMADE-EsCOT (2000) a respeito da didática da Educação Física. Em sua abordagem, ela dividiu esse campo de estudos nos níveis macro, relacionado à estrutura curricular da escola, meso, relacionado à organização dos conhecimentos para que se tornem acessíveis aos alunos, e micro, relacionado à intervenção direta dos professores com os alunos em sala de aula (AMADE-EsCOT, 2000, p.87).

Um aspecto a ressaltar é que tanto a abordagem de Mizukami (2004) quanto a abordagem de AmAde-Escot (2000) parecem permear a estrutura teórica apresentada por Grossman (1990) e, por consequência, a de SHuLman (1987). Ou seja, todas reconhecem o papel do conhecimento pedagógico geral, como salientou SHULMAN (1987), de abranger quatro dimensóes de conhecimento, relativas aos alunos e à aprendizagem; à gestão da sala de aula; ao currículo e à instrução; e às demais questôes concernentes ao processo de ensino e aprendizagem.

De maneira geral, se observa, na análise da proposta do conhecimento pedagógico geral, estreita relação com os fundamentos teórico-metodológicos da atuação docente dos futuros professores, no sentido de lhes oferecer condições de interagir em distintos âmbitos de ensino e aprendizagem, independentemente da área em que atuem.

A análise conjunta das propostas de SHulman (1987), Grossman (1990), Cochran, King e Deruiter (1991) e MizUKAMI (2004), sobre o conhecimento pedagógico geral, e da proposta de AMADE-EsCOT (2000), sobre a didática da Educação Física, evidencia a ligação visceral entre elas, selada principalmente pelos conhecimentos do currículo e da gestão da sala de aula. Essas questóes ganham destaque na proposta de Grossman (1990), quando descreve que o conhecimento do currículo inclui o "conhecimento dos materiais curriculares disponíveis para o ensino de um assunto particular", bem como o conhecimento sobre diferentes possibilidades de abordar o assunto com os alunos, seja num eixo "vertical", referente a uma aula ou a uma única intervenção pedagógica, seja num eixo "horizontal", referente ao planejamento das aulas e à distribuição e à organização dos conteúdos e dos objetivos ao longo do período letivo (Grossman, 1990, p.8, tradução nossa).

O raciocínio desenvolvido por Grossman parece relacionar-se intimamente com os estudos de METZLER, TJEERDSMA e Mozen (2000) e com as considerações de SEEL (1999) sobre a didática na formação inicial de professores, quando afirma:

Uma abordagem teórica da [didática], baseada em teorias de aprendizagem, sugere a adaptação do ensino para os processos de aprendizagem dos alunos [...]. Essa abordagem tem como objetivo analisar e detectar os procedimentos de ensino que parecem ser mais adequados para promover os processos de aprendizagem dos alunos (SEEL, 1999, p.15, tradução nossa).

Morine-Dershimer e Kent (1999) também integram o grupo de estudiosos que têm contribuído para a compreensão do conhecimento pedagógico geral. Dentre os mais significativos resultados de suas pesquisas, bem como da análise de outras investigações, os autores explicam, por exemplo, que os alunos aprendem mais quando novas informações são estruturadas e relacionadas com os seus conhecimentos e experiências anteriores, quando eles recebem feedbacks adequados sobre o seu desempenho. Os alunos aprendem mais quando os professores utilizam o tempo eficientemente, implementam estratégias de ensino e em grupo com elevados níveis de envolvimento, estabelecem regras e apresentam suas expectativas claramente, e evitam problemas ao introduzir, no início do ano letivo, um sistema de gestão e de execução consistente para o decorrer do ano (MORINEDershimer \& Kent, 1999, p.25, tradução nossa).

De modo geral, as reflexôes dos autores analisados, bem como as proposições de BEHETS e VERGAUWEN (2006), Grossman (2008), Metzler, Tjeerdsma e Mozen (2000), O’Sullivan e Doutis (1994), Rink (1997), Rovegno (2008), Schincariol (2002) e Whipple (2002), dão relevo às responsabilidades que pesam sobre os programas de formação inicial - de Educação Física e de outras áreas do conhecimento - no sentido de garantir a evolução do conhecimento pedagógico geral dos estudantes-professores. Para eles, há necessidade de que os programas de formação inicial implementem mecanismos e estratégias pedagógicas que permitam aos futuros professores o contato direto com situações reais de ensino e aprendizagem, como requisito para o pleno desenvolvimento do seu conhecimento pedagógico geral. 
A exemplo dos conhecimentos dos alunos e do conteúdo, se reconhece que a estruturação e o gradativo aperfeiçoamento do conhecimento pedagógico geral também forneçam ao estudante-professor algumas das condições necessárias para avançar consistentemente, durante a sua formação inicial, na construção e no aprimoramento do seu conhecimento pedagógico do conteúdo. (AMADE-Escot, 2000; CoCHRAN, King \& Deruiter, 1991; GraÇA, 2001; MizuKami, 2004; Segall, 2004; Shulman, 1987). Dita relação é sublinhada por GRAÇA (1997, p.86), quando descreve o conhecimento pedagógico do conteúdo como "uma amálgama de conteúdo e pedagogia, ou como fruto do casamento do conhecimento disciplinar com o conhecimento pedagógico geral".

Sob essa perspectiva, é enaltecida a importância do conhecimento pedagógico geral dentro da base de conhecimentos e sua relevância para a estruturação do conhecimento pedagógico do conteúdo e a formação docente e profissional dos futuros professores de Educação Física.

\section{Conhecimento do contexto}

Para além de assimilarem os pontos de vista de Shulman e de Grossman, autores como Cochran, KInG e Deruiter (1991), Graber (1995), O'Sullivan e Doutis (1994), Rink (1997), Rovegno (1994, 1995, 2006, 2008), Rovegno e Dolly (2006), Schincariol (2002), Whipple (2002), ZeICHNER (1993), entre outros, acrescentam a participação dos aspectos sociais, políticos, culturais e organizacionais do ambiente da sala de aula na maneira como o professor ensina, o que ratifica o relevo e a autonomia do conhecimento do contexto dentro da base de conhecimentos para o ensino.

Dos estudos de Doyle (1986), Grossman (2008), Grossman e McDonald (2008), Rink (1997), RoVEGNo (2006), Whipple (2002) e Zeichner (1993), que tratam dos conhecimentos dos professores, podem ser extraídas fortes evidências que ressaltam, veementemente, a necessidade de os programas de formação inicial prestarem atenção na estrutura do conhecimento do contexto dos futuros professores. Tais evidências encaminham a interpretação de que, inicialmente, se faz necessário o desenvolvimento, por parte dos estudantes-professores, de uma compreensão aprofundada do contexto particular no qual atuarão, para somente então, adquirirem condições de adaptar os demais integrantes da base de conhecimentos às especificidades do contexto. De modo sintético, a mensagem dos autores (Doyle, 1986; Grossman, 2008; Grossman \& McDonald, 2008;
Rink, 1997; Rovegno, 2006; Whipple, 2002; ZeICHNER, 1993) é a de que, para serem usados em suas práticas pedagógicas, os conhecimentos dos futuros professores necessitam ser adaptados à especificidade do contexto de ensino e aprendizagem e, muito concretamente, às características circunstanciais do ambiente onde se realizam as aulas, e às peculiaridades de determinado grupo de alunos. O contexto de ensino e aprendizagem, nesse caso, é formado a partir da interação dos professores com diferentes alunos, que advêm de endereços sociais particulares e se inserem em realidades escolares e de salas de aula específicas.

Ao abordar o conhecimento do contexto, SHULMAN (1987) propõe, mesmo que indiretamente, sua estruturação em três diferentes âmbitos. Para o autor, a atuação docente do professor se dá desde o trabalho com os alunos individualmente, em grupos ou com toda a turma; passa pela administração e gestão escolares; e alcança as particularidades sociais e culturais da comunidade onde se inserem a escola e os alunos. Essa abordagem é compartilhada por Grossman (1990), Grossman e McDonald (2008) e Zeichner (1993), que também analisam o conhecimento do contexto dos professores a partir da sua relação com os alunos, com a escola e com a comunidade.

Diante disso, esses três âmbitos do conhecimento do contexto podem ser denominados, respectivamente, microcontexto, da sala de aula, mesocontexto, da escola, e macrocontexto, da comunidade, sendo todos analisados sob o ponto de vista da formação inicial e de seus reflexos na qualificação docente dos futuros professores de Educação Física.

Além das importantes contribuiçōes das propostas de Cochran, King e Deruiter (1991), de Grossman (1990), de Shulman (1987) e de Zeichner (1993) para a compreensão do conhecimento do contexto, é nos estudos de Doyle (1986) sobre a organização e gestão da sala de aula, de Rink (1997), sobre o papel do contexto na aprendizagem docente, e de SIEDENTOP (2002b), sobre a perspectiva ecológica da sala de aula, que essa intrincada rede de relaçōes - estabelecida nas situaçōes reais de ensino e aprendizagem - adquire estrutura, consistência e relevância para a investigação relacionada ao processo de formação inicial de professores de Educação Física. Mesmo vinculadas ao contexto das aulas, da sala de aula, do processo de ensino e aprendizagem e das relações dos alunos entre si e com os professores, é importante a consideração das perspectivas dos autores na esfera do conhecimento do contexto.

Ao analisar os processos de organização e de gestão da sala de aula, DoYLE (1986) destaca o próprio ambiente onde são desenvolvidas as aulas, no que 
tange às várias circunstâncias imediatas que afetam a natureza da ordem e da atuação do professor. Conforme explica o autor, as características intrínsecas do contexto da sala de aula, ou seja, "simultaneidade, multidimensionalidade, imediaticidade, imprevisibilidade, e caráter público e histórico" (Doyle, 1986, p.394-5, tradução nossa), já estão em vigor antes mesmo de os professores e os alunos chegarem à sala de aula. São esses elementos que estruturam o cenário no qual se desenvolve a aula, impondo pressões que modelam a tarefa de ensinar e que exigem intervenção qualificada por parte do professor.

Nessa esteira, RinK (1997) esclarece que os professores, em especial os de Educação Física, necessitam ensinar uma ampla variedade de conteúdos para uma ampla gama de alunos (de diferentes idades, gêneros, etnias, orientações culturais, habilidades, e experiências) em contextos muito diversos e com quantidades variáveis de apoio. Alunos e professores de uma mesma classe provavelmente responderão de diferentes maneiras em diferentes momentos, dependendo do seu contexto social e do que está acontecendo em suas vidas pessoais em um dado período. $\mathrm{O}$ ensino não é apenas complexo, mas é também realizado em ambientes muito diversos e dinâmicos (p.17, tradução nossa).

Em consonância com as abordagens de DoyLe (1986) e de Rink (1997), Siedentop (2002b) também enfatiza a necessidade de desenvolvimento do conhecimento do contexto dos futuros professores de Educação Física, ao afirmar que

o ensino não se parece com a preparação para um jogo ou um recital, como uma palestra ou um seminário na universidade. Os professores ministram aulas o dia todo, cinco dias por semana, e durante todo o ano letivo. Professores e alunos têm que viver juntos e pacificamente por todas as aulas, ao longo do ano escolar. (Siedentop, 2002b, p.428, tradução nossa).

Esse amplo leque de responsabilidades que recai sobre o professor de Educação Física também recebeu atenção de Ramos, Graça e Nascimento (2007). A exemplo de Doyle (1986), Rink (1997) e Siedentop (2002b), a atuação docente do professor de Educação Física, na perspectiva dos autores, também se caracteriza como multidimensional, imprevisível e com "simultaneidade de situaçōes, cada qual com uma dinâmica própria, exigindo do professor procedimentos complexos" que atendam às "características circunstanciais e inesperadas dos eventos e das particularidades dos contextos", seja dos alunos e da sala de aula, seja da escola e da comunidade (RAmos, GraçA \& NASCIMENTO, 2007, p.1).
Menck (1995) aprofunda essa reflexão ao defender, até mesmo, que o microcontexto, na verdade, não é ele em si, mas apenas uma representação simbólica da realidade e, portanto, dos meso e macrocontextos. Para o autor, a atuação docente do professor pressupõe interpretar essa realidade e considerá-la no planejamento e na gestão de suas práticas pedagógicas.

De modo geral, a mescla dos estudos dos diferentes autores apresentados, além de dar relevo ao conhecimento do contexto na formação dos futuros professores de Educação Física, permite o retorno à própria proposta de SHULMAN (1987), e aos três âmbitos desse conhecimento.

Os futuros professores de Educação Física necessitam não apenas conhecer as peculiaridades de cada um desses três âmbitos do conhecimento do contexto, como também considerá-las cuidadosa e criteriosamente no planejamento, na implementação e na gestão de suas práticas pedagógicas. Espera-se, inclusive, que os estudantes-professores participem, organizem, promovam e se engajem em diferentes iniciativas, atividades e eventos, seja na área de Educação Física ou na área de outras disciplinas curriculares, seja na escola ou na comunidade.

Percebe-se, pois, que o conhecimento do contexto adquire caráter específico e fundamental na formação dos futuros professores de Educação Física, já que provém do contato, da experiência e da relação direta e concreta com os papéis e as responsabilidades que necessitarão assumir, com a realidade da escola, suas tarefas e suas normas, e com as dinâmicas inerentes à interação dos diferentes atores escolares, sejam eles os alunos, os professores, os coordenadores, os diretores ou os funcionários técnico-administrativos, sejam eles os pais dos alunos.

Quanto maiores forem a proximidade e o conhecimento sobre o contexto de vida dos alunos e de suas comunidades, e sobre o ambiente escolar e de realização das aulas, de mais elementos os futuros professores disporão tanto para planejar e gerir suas práticas pedagógicas quanto para alcançar distintos objetivos, seja da disciplina de Educação Física para com os alunos, seja dos alunos para com as aulas de Educação Física.

O desenvolvimento dos conhecimentos dos futuros professores de Educação Física sobre cada um dos micro, meso e macrocontextos reverterá em benefício dos próprios micro, meso e macrocontextos, qualificando sua atuação docente e profissional e potencializando, consequentemente, o alcance dos objetivos educacionais e de formação dos alunos.

Parece inevitável que, na análise isolada de quaisquer desses três âmbitos do conhecimento do 
contexto, acabem por emergir, também, os outros dois, à medida que todos se relacionam intrinsecamente, se perpassam, interagem continuamente e se complementam para constituir a individualidade do contexto de vida de cada aluno, de cada sala de aula, de cada escola e de cada comunidade. Dita relação fica evidente, ainda, uma vez que as características da comunidade influenciam nos conhecimentos e nas concepções dos alunos, os quais, individual e coletivamente, reverberam esses conhecimentos e essas concepçôes de volta para a própria comunidade, numa relação recíproca que pode, ou não, ser mediada pela escola e pelos professores.

Há que se reconhecer, ainda, a dificuldade em divisar claramente os diferentes âmbitos do conhecimento do contexto, visto que suas fronteiras muitas vezes se diluem umas nas outras. Exemplo disso são os pais dos alunos, que podem, por um lado, apenas fazer parte da comunidade que circunda a escola, inserindo-se, portanto, mais no macrocontexto e, por outro lado, podem conviver mais proximamente dos professores e do ambiente escolar e, até mesmo, participar da gestão escolar como representantes da comunidade, inserindo-se, portanto, mais no mesocontexto.

Tal como observado nos conhecimentos dos alunos, do conteúdo e pedagógico geral, destaca-se que a estruturação e o gradativo aperfeiçoamento do conhecimento do contexto também proporcionarão ao estudante-professor algumas das condições necessárias para encaminhar consistentemente, durante a sua formação inicial, a construção e o desenvolvimento do seu conhecimento pedagógico do conteúdo (AMADE-EsCOT, 2000; Cochran, King \& Deruiter, 1991; GraçA, 1997, 2001; Grossman, 1990; MizuKami, 2004; SEGALl, 2004; SHULMAN, 1987). A importância da relação entre o conhecimento do contexto e o conhecimento pedagógico do conteúdo é sublinhada por diferentes autores (Graber, 1995; Rovegno, 1994, 1995, 2008; SCHINCARIOL, 2002; WhIPPLE, 2002) e sintetizada por VeAL e MAKInster (1999), quando se referem ao conhecimento pedagógico do conteúdo como a

capacidade de traduzir o conteúdo da matéria

de ensino para um diversificado grupo de alunos usando múltiplas estratégias e métodos de ensino e de avaliação, levando em consideração as limitaçôes contextuais, culturais e sociais do ambiente de aprendizagem (p.11, tradução nossa).

Esses constituem elementos que enaltecem o conhecimento do contexto dentro da base de conhecimentos e sua relevância para a estruturação do conhecimento pedagógico do conteúdo e a formação docente dos futuros professores de Educação Física.

\section{Conhecimento pedagógico do conteúdo}

O conhecimento apontado por SHULMAN (1987) e que se sobressai dentro da base de conhecimentos para o ensino, em função da sua relevância não apenas para a atuação docente do professor, mas também por sua importância nos processos de formação inicial e continuada, é o conhecimento pedagógico do conteúdo. A tônica da sua relação com os demais integrantes da base de conhecimentos é objeto de análise de GraçA (1997), quando explica que problemas de demarcação conceptual e filiação do conhecimento pedagógico do conteúdo decorrem também das suas características genealógicas. Definido como uma amálgama de conteúdo e pedagogia, ou como fruto do casamento do conhecimento disciplinar com o conhecimento pedagógico geral, o constructo do conhecimento pedagógico do conteúdo transporta a ambiguidade da sua herança advinda da diluição das fronteiras entre ele e os seus progenitores (p.86).

Compartilhada por diferentes autores (ABELL, 2008; Abell, Rogers, Hanuscin, Lee \& Gagnon, 2009; Cochran, Deruiter \& King, 1993; Cochran, King \& Derutter, 1991; Gess-Newsome, 1999; GraçA, 2001; Grossman, 1990; JenKInS \& Veal, 2002; KInD, 2009; Marcon, 2011; MizuKami, 2004; Morine-Dershimer \& Kent, 1999; Park \& Oliver, 2008; Segall, 2004; Shulman, 1986, 1987; Veal \& Makinster, 1999), a problemática à qual se refere GRAÇA (1997) advém justamente da centralidade do papel desempenhado pelo conhecimento pedagógico do conteúdo dentro da base, já que tem a responsabilidade de congregar, reunir, fazer interagir e analisar em conjunto seus demais integrantes. Ou seja, o conhecimento pedagógico do conteúdo refere-se a uma construção pessoal do estudante-professor que, ao entrelaçar todas as suas vivências e combinar todos os seus conhecimentos, estrutura uma concepção particular e aprofundada sobre o assunto, visando ao seu ensino.

Ao analisar os conhecimentos que viabilizam o alcance desses objetivos, Grossman (1990) propôs uma subdivisão do conhecimento pedagógico do conteúdo em quatro diferentes categorias, designadamente os conhecimentos dos propósitos para o ensino do conteúdo; curricular do conteúdo; das estratégias de ensino; e sobre a compreensão dos alunos.

$\mathrm{Na}$ primeira categoria, o conhecimento dos propósitos para o ensino do conteúdo mantém estreita relação com os objetivos estabelecidos pelo estudanteprofessor para o ensino de determinado conteúdo para um grupo de alunos específico. Por isso, esse 
conhecimento se apoia nas concepções pessoais do estudante-professor a respeito de sua própria atuação docente, por meio das quais estabelece prioridades sobre o que e por que ensinar, e se reflete nas suas escolhas e decisões metodológicas nas práticas pedagógicas (ENNIS, 1994; GraÇA, 1997, 2001; GROSSMAN, 1990; Ramos, GraÇA \& NaSCIMENTO, 2008).

O conhecimento curricular do conteúdo, por sua vez, refere-se aos meios empregados pelo estudanteprofessor para gerir o conteúdo a ser ensinado, organizando-o e o preparando em função das particularidades do contexto de ensino e aprendizagem, dos diferentes níveis de ensino e dos seus objetivos. A partir do aperfeiçoamento do conhecimento curricular do conteúdo, o estudante-professor tem condiçôes de situar e de justificar a presença de determinado conteúdo dentro da estrutura curricular, tomando ciência da relação desse com os demais conteúdos curriculares (Grossman, 1990; VeAL \& Makinster, 1999). De acordo com Ramos, GraçA e NASCIMENTO (2008), o conhecimento curricular do conteúdo na área de Educação Física envolve conhecimentos que permitem ao professor elaborar, adaptar e aplicar propostas pedagógicas reconhecendo a seqüência que deve ser dada ao conteúdo e o nível de complexidade das atividades/tarefas. Ele contempla o conhecimento dos programas, e de como usar os manuais, baterias de exercícios, fichas de ensino, equipamentos de audiovisual, recursos didáticos vários e dos modelos curriculares (p.166).

O conhecimento das estratégias de ensino, como o próprio nome evidencia, diz respeito às diversas maneiras pelas quais se pode levar a cabo o ensino de um conteúdo para um grupo de alunos em particular (Grossman, 1990). Relacionado ao "quando" determinado "conteúdo ou método de ensino" é mais apropriado, o conhecimento das estratégias reporta-seà forma como o estudante-professor de Educação Física "representa a matéria, os modos de instrução, demonstrações, explicações, analogias, metáforas, exemplos, tarefas de aprendizagem ou exercícios [...] para fazer o aluno compreender um tópico específico da matéria" (RAmos, GraçA \& NASCimento, 2008, p.166).

Por fim, o conhecimento sobre a compreensão dos alunos advoga em favor da necessidade de serem considerados todos os conhecimentos, todas as experiências e concepções dos alunos que, construídas a partir de sua história de vida, influenciam diretamente na magnitude do conhecimento de cada um deles sobre cada um dos conteúdos abordados nas situações de ensino e aprendizagem (Grossman, 1990). Nesse sentido, os futuros professores de Educação Física necessitam "conhecer os alunos e suas características, bem como saber como aprendem, saber identificar sinais importantes em suas manifestações e expressões sobre o que sabem sobre a matéria”, de modo a descobrir quais são "as suas confusōes, erros típicos, concepçōes pessoais e falsas concepçôes” (GRAÇA, 2001, p.116).

O conhecimento sobre a compreensão dos alunos, seja um dos componentes do conhecimento do contexto (Shulman, 1987), uma subcategoria do conhecimento pedagógico do conteúdo (GROSSMAN, 1990), seja um dos integrantes da base de conhecimentos para o ensino (COCHRAN, KIng \& DERUITER, 1991), constitui, assim, "um tipo de conhecimento que se situa no fulcro da ideia de conhecimento pedagógico do conteúdo, porque ele é a referência central para proceder às transformações pedagógicas ou didáticas dos conteúdos" (GRAÇA, 2001, p.116).

Considerando esse cenário construído por estudos de vários autores ao longo dos últimos anos, o conhecimento pedagógico do conteúdo pode ser compreendido como aquele que o estudante-professor utiliza para, a partir dos seus objetivos, da realidade dos alunos e das características do contexto de ensino e aprendizagem, convocar, gerir e fazer interagir os conhecimentos da base de conhecimentos para o ensino, visando à adaptação, à transformação e à implementação do conhecimento do conteúdo a ser ensinado, de modo a torná-lo compreensível e ensinável aos alunos.

Essa síntese da definição do conhecimento pedagógico do conteúdo encontra respaldo teórico, justamente: no modelo da base de conhecimentos para o ensino proposto por Cochran, King e Deruiter (1991), que é integrado pelos conhecimentos dos alunos, do conteúdo, pedagógico geral, do contexto, e pedagógico do conteúdo; nas quatro categorias que sustentam o conhecimento pedagógico do conteúdo, elaboradas por Grossman (1990), ou seja, os conhecimentos dos propósitos para o ensino do conteúdo, curricular do conteúdo, das estratégias de ensino, e sobre a compreensão dos alunos; e na própria raiz do conhecimento pedagógico do conteúdo, que tem em SHulman (1986) a sua definição primeira:

[O] conhecimento pedagógico do conteúdo incorpora os aspectos do conteúdo mais pertinentes ao seu ensino. Dentro da categoria do conhecimento pedagógico do conteúdo se inclui, além dos tópicos mais regularmente ensinados sobre um assunto, as formas mais úteis de representaçāo dessas idéias, as analogias mais poderosas, ilustraçōes, exemplos, explicações e demonstraçōes - em uma palavra, as formas de representar e de formular o assunto para que se torne mais compreensivel para os outros 
[...]. [Ele] também inclui uma compreensão a respeito dos aspectos que tornam a aprendizagem de determinado conteúdo mais fácil ou difícil: as concepções e preconceitos que os alunos de diferentes idades e origens trazem com eles para a aprendizagem (p.9, tradução nossa).

A tarefa de dissecar o constructo do conhecimento pedagógico do conteúdo, a partir da definição anteriormente apresentada, permite lançar luz sobre a diluição e a mescla das propostas de SHULMAN $(1986,1987)$, de Grossman (1990) e de Cochran, King \& Deruiter (1991) uma na outra, aclarando a interatividade que pauta sua relação com todos os conhecimentos e elementos formativos no seu entorno, nos quais o conhecimento pedagógico do conteúdo tanto influencia quanto, e dos quais, concomitantemente sofre influência.

Essa mescla se evidencia da seguinte maneira: o conhecimento pedagógico do conteúdo pode ser compreendido como aquele que o estudanteprofessor utiliza para, a partir dos seus objetivos (conhecimento dos propósitos para o ensino do conteúdo - Grossman); da realidade dos alunos (conhecimento dos alunos - Cochran); e das características do contexto de ensino e aprendizagem (conhecimento do contexto - Cochran); convocar (conhecimento pedagógico do conteúdo - Shulman), gerir (conhecimento curricular do conteúdo - Grossman); e fazer interagir (conhecimento pedagógico do conteúdo - Shulman); os conhecimentos da base de conhecimentos para o ensino (conhecimentos dos alunos, do conteúdo, pedagógico geral e do contexto - Cochran); visando à adaptação, à transformação e à implementação (conhecimento das estratégias de ensino - Grossman); do conhecimento do conteúdo a ser ensinado (conhecimento do conteúdo - Cochran); de modo a torná-lo compreensível e ensinável aos alunos (essência do conhecimento pedagógico do conteúdo - Shulman).

Perspectiva semelhante também foi apresentada por CoCHRAN, King e DerUiter (1991), ao interpretarem o conhecimento pedagógico do conteúdo como um tipo de conhecimento que é exclusivo para professores, e de fato é o que o ensino significa. Trata-se da maneira como os professores relacionam os seus conhecimentos pedagógicos (o que sabem sobre o ensino) com os seus conhecimentos sobre o assunto (o que sabem sobre aquilo que ensinam), no contexto escolar, para o ensino de determinados alunos. $\mathrm{O}$ conhecimento pedagógico do conteúdo compreende a integração ou a síntese do conhecimento pedagógico dos professores e do seu conhecimento sobre o assunto (p.4, grifos dos autores, tradução nossa).
A relação entre os integrantes da base de conhecimentos para o ensino e o processo de construção e de utilização do conhecimento pedagógico do conteúdo também recebeu atenção especial nos estudos de CoCHRAN, DERUITER e KING (1993), quando passaram a questionar a inércia das propostas de SHULMAN (1987) e de Grossman (1990). As mais significativas contribuições de Cochran, Deruiter e KIng (1993) para esse campo de estudo dizem respeito à necessidade de se transpor a interpretação rígida e estanque do tradicional "pedagogical content knowledge", bem como de se estruturar uma abordagem mais flexível e dinâmica, relativa ao "pedagogical content knowing".

A principal virtude desse enfoque reside justamente no destaque ao caráter dinâmico do processo de construção e de expressão do conhecimento pedagógico do conteúdo. Cochran, Deruiter e KING (1993) representaram esse movimento por meio do uso do termo "knowing", que pode ser traduzido da Língua Inglesa para a Língua Portuguesa de diferentes maneiras, entre elas como sabendo e conhecendo, no gerúndio, o que reforça a ideia de um processo em pleno andamento, em plena execução e que se estende ao longo do tempo.

Além de ratificar a dinamicidade defendida por Cochran, Deruiter e King (1993), a estrutura teórico-conceitual apresentada anteriormente permite o retorno à concepção inicial de SHULMAN (1987) sobre a presença e o papel desempenhado pelo conhecimento pedagógico do conteúdo dentro da base de conhecimentos para o ensino, bem como a compreensão da especificidade da própria base de conhecimentos do professor:

A chave para distinguir a base de conhecimentos para o ensino reside na intersecção do conteúdo com a pedagogia, na capacidade do professor de transformar o seu conhecimento do conteúdo em formas que sejam pedagogicamente poderosas e adaptáveis às variações de capacidade e de experiências apresentadas pelos alunos (SHulman, 1987, p.15, tradução nossa).

Observa-se, nesses casos, bem como em outros estudos que investiram esforços para elucidar os meandros dessa relação (BENHAM, 2002; GessNewsome, 1999; Jenkins \& Veal, 2002; Kind, 2009; Marcon, 2011; Park \& Oliver, 2008), que a evolução do conhecimento pedagógico do conteúdo está diretamente atrelada às oportunidades que o estudante-professor tem de se defrontar com diferentes dilemas e situaçôes-problema, fundamentalmente em contextos reais de ensino e aprendizagem. Por manifestarem características 
diversas, essas estratégias instigam o conhecimento pedagógico do conteúdo a requisitar e a gerir os demais integrantes da base de conhecimentos que se relacionem com o assunto e com o contexto, no sentido de buscar solução às situações-problema e de alcançar os objetivos estabelecidos para as práticas pedagógicas (BEHETS \& VERGAUWEN, 2006; GRABER, 1995; Grossman \& McDonald, 2008; Hegarty, 2000; Marques, 2000; Park et al., 2010; Pimenta, 2002; SCHINCARIOL, 2002; ZeICHNER, 2010).

Em sendo assim, será por intermédio dessa gestão dos conhecimentos na base de conhecimentos que o conhecimento pedagógico do conteúdo, partindo dos objetivos da situação de ensino e aprendizagem, das características do contexto e da realidade e das necessidades dos alunos, adaptará e/ou transformará a própria concepção do estudante-professor sobre o assunto que, por sua vez, possibilitará a compreensão, o entendimento e, consequentemente, a aprendizagem de cada um dos seus alunos. É justamente isso que propõem, em seus estudos, autores como GraÇA (2001), Marcon (2011), Mizukami (2004), Park e Oliver (2008), Segall (2004) e Shulman (1987).

Por ser resultado dessa confluência dos outros quatro integrantes da base de conhecimentos, o desenvolvimento do conhecimento pedagógico do conteúdo se potencializa na interação do estudante-professor com a atuação docente, esteja ela

\section{Considerações finais}

Tendo em vista a análise aqui apresentada, percebe-se que todos os elementos constituintes do processo de formação inicial, em conjunto com as vivências docentes extracurriculares e com as experiências de vida, se somam e se interligam de maneira a favorecer a estruturação da base de conhecimentos para o ensino e a construção do próprio conhecimento pedagógico do conteúdo dos estudantes-professores de Educação Física.

As proposiçôes de vários autores, fundamentalmente de Shulman $(1986,1987)$, de Grossman (1990) e de Cochran, King e Deruiter (1991), permitem estruturar uma proposta que, além de demonstrar a integração entre a base de conhecimentos para o ensino, seus diferentes componentes e o conhecimento pedagógico do conteúdo, também evidencia o papel desempenhado pelo próprio conhecimento pedagógico do conteúdo nas situações de ensino e aprendizagem ao longo da formação inicial vinculada ao programa de formação inicial ou às suas experiências pedagógicas extracurriculares (BEHETS \& Vergauwen, 2006; Calderhead, 1988; Hegarty, 2000; Jenkins \& Veal, 2002; Marcon, 2011; Marques, 2000; Pimenta, 2002). A aproximação ao contexto de ensino e aprendizagem favorecerá a contínua estruturação e o fortalecimento do conhecimento pedagógico do conteúdo e esculpirá, aos poucos, a personalidade docente e o perfil profissional do futuro professor de Educação Física.

O papel desempenhado pelo conhecimento pedagógico do conteúdo sublinha a relevância de sua participação, tanto na atuação docente, em situaçōes de ensino e aprendizagem com alunos, quanto nos processos e períodos de aprendizagem e de aperfeiçoamento docente, seja na formação inicial do estudante-professor de Educação Física, seja na formação continuada do professor na Educação Básica.

Essas são questões que, além de justificarem o interesse pelo tema, também reforçam a necessidade de se dedicar especial atenção aos caminhos seguidos para a construção e para a evolução do conhecimento pedagógico do conteúdo dos estudantesprofessores durante a formação inicial em Educação Física, fundamentalmente por meio da sua relação com a base de conhecimentos para o ensino nas diferentes modalidades de práticas pedagógicas, ministradas pelos futuros professores.

em Educação Física. A partir dessa reinterpretação teórico-conceitual, o conhecimento pedagógico do conteúdo pode ser compreendido como aquele que o estudante-professor utiliza para, a partir dos seus objetivos, da realidade dos alunos e das características do contexto de ensino e aprendizagem, convocar, gerir e fazer interagir os conhecimentos da base de conhecimentos para o ensino, visando à adaptação, à transformação e à implementação do conhecimento do conteúdo a ser ensinado, de modo a torná-lo compreensível e ensinável aos alunos.

Para o alcance desses objetivos na formação inicial em Educação Física, a literatura consultada ressalta a necessidade de aproximar o contexto de formação do contexto de atuação profissional do professor na Educação Básica e, principalmente, de ampliar as oportunidades para que os estudantes-professores se posicionem diante de diferentes dilemas e situações-problema ao longo de todo o processo 
de formação inicial. Essa postura, por parte dos programas de formação inicial em Educação Física, repercutirá incisivamente no processo de construção do conhecimento pedagógico do conteúdo e, por consequência, no delineamento da personalidade docente e profissional dos futuros professores.

\begin{abstract}
Reinterpretation of the theoretical conceptual framework of pedagogical content knowledge

The pedagogical content knowledge integrates the knowledge base for teaching - body of knowledge needed by the teacher - together with the knowledge related to the students' characteristics, the topic of the classes, general pedagogy, and contexts of learning. Taking into account its importance in the formation of prospective teachers, this essay aimed to analyze the framework of the base of knowledge of future Physical Education teachers from the perspective of pedagogical content knowledge, seeking to contribute with the debate on the role of this knowledge on the planning, implementation of teaching and learning situations, and on the teaching formation of prospective teachers as well. Concerning the theoretical framework analyzed, the pedagogical content knowledge can be comprehended as that the teacher-student utilize to, from its objectives, reality of the students, and characteristic of the teaching and learning context, summon, manage and make the knowledge of the knowledge base for teaching interact, seeking the adaptation, transformation, and implementation of the content knowledge to be taught, so that it becomes comprehensible and teachable to students. To achieve these objectives, the literature suggests the approach of the initial context of teacher education in Physical Education of that the professional work of teachers in basic education, in addition to increasing opportunities for prospective teachers are faced with different dilemmas and problematic situations along initial training. Such strategies encourage the construction of pedagogical content knowledge and, consequently, the delineation of teacher personality of future teachers.
\end{abstract}

UnITERMS: Formation of teachers; Teaching; Teaching preparation; Knowledge base.

\title{
Referências
}

ABELL, S.K. Twenty years later: Does pedagogical content knowledge remain a useful idea? International Journal of Science Education, London, v.30, n.10, p.1405-6, 2008. Disponível em: <http://www.informaworld. com/10.1080/09500690802187041>. Acesso em: 15 set. 2010.

ABELL, S.K.; ROGERS, M.A.P.; HANUSCIN, D.L.; LEE, M.H.; GAGNON, M.J. Preparing the next generation of science teacher educators: a model for developing PCK for teaching science teachers. Journal of Science Teacher Education, Columbus, v.20, p.77-93, 2009. Disponível em: <http://www.springerlink.com/content/a1j4p781335r2548/fulltext.pdf>. Acesso em: 5 jun. 2010. ALTET, M. As competências do professor profissional: entre conhecimentos, esquemas de ação e adaptação, saber analisar. In: PAQUAY, L.; PERRENOUD, P.; ALTET, M.; CHARLIER, É. (Orgs.). Formando professores profissionais: quais estratégias? Quais competências? Porto Alegre: Artmed, 2001. p.23-35.

AMADE-ESCOT, $\mathrm{C}$. The contribution of two research programs on teaching content: "pedagogical content knowledge" and "didactics of physical education". Journal of Teaching in Physical Education, Champaign, v.20, n.1, p.78-101, 2000. AYVAZO, S.; WARD, P.; STUHR, P.T. Teaching and assessing content knowledge in preservice physical education: teachers' effectiveness depends not only on what they know, but on how they teach it. Journal of Physical Education, Recreation \& Dance, Reston, v.81, n.4, p.40-5, 2010. Disponível em: <http://find.galegroup.com/gtx/infomark.do?\&contentSet=IACDocuments\&type $=$ retrieve\&tabID=T002\&prodId=AONE\&docId=A225603607\&source $=$ gale\&srcprod $=$ AONE\&userG roupName=ucs\&version=1.0>. Acesso em: 27 ago. 2010.

BEHETS, D.; VERGAUWEN, L. Learning to teach in the field. In: KIRK, D.; MacDONALD, D.; O'SULLIVAN, M. (Orgs.). Handbook of physical education. London: Sage, 2006. p.407-24. 
BENHAM, R.H. Expertise in sport instruction: examining the pedagogical content knowledge of expert golf instructors. 2002. 197 f. (Doctoral thesis) - Department of Kinesiology, The Michigan State University, Michigan, 2002. Disponível em: <http:// proquest.umi.com/pqdweb?did=765985091\&Fmt=7\&clientId=37541\&RQT=309\&VName=PQD>. Acesso em: 11 out. 2008. CALDERHEAD, J. The development of knowledge structures in learning to teach. In: CALDERHEAD, J. (Org.). Teachers' professional learning. London: Falmer Press, 1988. p.51-64.

CHEN, W. Learning the skill theme approach: salient and problematic aspects of pedagogical content knowledge. Education, [S.1.\}, v.125, n.2, p.194-212, 2004.

COCHRAN, K.F.; DERUITER, J.A.; KING, R.A. Pedagogical content knowing: an integrative model for teacher preparation. Journal of Teacher Education, Washington, v.44, n.4, p.263-72, 1993.

COCHRAN, K.F.; KING, R.A.; DERUITER, J.A. Pedagogical content knowledge: a tentative model for teacher preparation. In: ANNUAL MEETING OF THE AMERICAN EDUCATIONAL RESEARCH ASSOCIATION, 1991, Chicago. Proceedings... Chicago: AERA, 1991.

DARIDO, S.C. Teoria, prática e reflexão na formação profissional em Educação Física. Motriz: Revista da Educação Física, Rio Claro, v.1, n.2, p.124-8, 1995.

DARLING-HAMMOND, L. Constructing 21st-century teacher education. Journal of Teacher Education, Washington, v.57, n.3, p.300-15, 2006. Disponível em: <http://find.galegroup.com/gtx/infomark.do?\&contentSet=IAC-Documents \&type=retrieve\&tabID=T002\&prodId=AONE\&docId=A145631463\&source=gale\&srcprod=AONE\&userGroupNam e=ucs\&version=1.0>. Acesso em: 20 ago. 2010.

DOYLE, W. Classroom organization and management. In: WITTROK, M. (Org.). Handbook of research on teaching. New York: MacMillan, 1986. p.392-431.

ENNIS, C. Knowledge and beliefs underlying curricular expertise. Quest, Champaign, v.46, n.2, p.164-75, 1994.

FENSTERMACHER, G.D. The knower and the known: the nature of knowledge in research on teaching. Review of Research in Education, Itasca, v.20, p.3-56, 1994.

FIGUEIREDO, Z.C.C. Formação docente em Educação Física: experiências sociais e relação com o saber. Revista Movimento, Porto Alegre, v.10, n.1, p.89-111, 2004.

GARCIA, R.P. Para um ensino superior com qualidade. Revista Portuguesa de Ciências do Desporto, Porto, v.1, n.1, p.33-43, 2001.

GESS-NEWSOME, J. Pedagogical content knowledge: an introduction and orientation. In: GESS-NEWSOME, J. (Org.). Examining pedagogical content knowledge: the construct and its implications for science education. Hingham: Kluwe Academic, 1999. p.3-23.

GRABER, K.C. The influence of teacher education programs on the beliefs of student teachers: general pedagogical knowledge, pedagogical content knowledge, and teacher education course work. Journal of Teaching in Physical Education, Champaign, v.14, n.2, p.157-78, 1995.

GRAÇA, A. O conhecimento pedagógico do conteúdo no ensino do basquetebol. 1997. $331 \mathrm{f}$. Tese (Doutorado em Ciências do Desporto) - Faculdade de Desporto, Universidade do Porto, Porto, 1997.

O conhecimento pedagógico do conteúdo: o entendimento entre a pedagogia e a matéria. In: GOMES, P.B.; GRAÇA, A. (Org.). Educação física e desporto na escola: novos desafios, diferentes soluçôes. Porto: FCDEF-UP, 2001. p.107-20.

GRÉHAIGNE, J.-F.; GODBOUT, P. Tactical knowledge in team sports from a constructivist and cognitivist perspective. Quest, Champaign, v.47, n.4, p.490-505, 1995.

GROSSMAN, P. The making of a teacher: teacher knowledge and teacher education. New York: Teachers College Press, 1990. Responding to our critics: from crisis to opportunity in research on teacher education. Journal of Teacher Education, Washington, v.59, n.1, p.10-24, 2008. Disponível em: <http://find.galegroup.com/gtx/infomark. do?\&contentSet=IAC-Documents\&type=retrieve\&tabID=T002\&prodId=AONE\&docId=A173463292\&source=gale \&srcprod=AONE\&userGroupName=ucs\&version=1.0>. Acesso em: 20 ago. 2010.

GROSSMAN, P.; McDONALD, M. Back to the future: directions for research in teaching and teacher education. American Educational Research Journal, Washington, v.45, n.1, p.184-205, 2008. Disponível em: <http://aer.sagepub.com/ content/45/1/184>. Acesso em: 14 set. 2010.

GROSSMAN, P.; WILSON, S.; SHULMAN, L. Teacher of substance: subject matter knowledge for teaching. In: REYNOLDS, M. (Org.). Knowledge base for the beginning teacher. New York: Pergamon, 1989. p.23-36.

HEGARTY, S. Teaching as a knowledge-based activity. Oxford Review of Education, Oxford, v.26, n.3/4, p.451-65, 2000. Disponível em: <http://search.ebscohost.com/login.aspx?direct=true\&db=aph\&AN=3893569\&site=ehostlive\&scope $=$ site $>$. Acesso em: 14 set. 2009. 
INTRATOR, S.M. Beginning teachers and the emotional drama of the classroom. Journal of Teacher Education, Washington, v.57, n.3, p.232-40, 2006. Disponível em: <http://find.galegroup.com/gtx/infomark.do?\&contentSet=IAC-Do cuments\&type $=$ retrieve $\&$ tabID $=$ T002\&prodId $=$ AONE \&docId $=$ A1 $45631455 \&$ source $=$ gale $\&$ srcprod $=$ AONE \&userGro upName=ucs\&version=1.0>. Acesso em: 20 ago. 2010.

JENKINS, J.M.; VEAL, M.L. Preservice teachers' PCK development during peer coaching. Journal of Teaching in Physical Education, Champaign, v.22, n.1, p.49-68, 2002.

KIND, V. Pedagogical content knowledge in science education: Perspectives and potential for progress. Studies in Science Education, Leeds, v.45, n.2, p.169-204, 2009. Disponível em: <http://www.informaworld. com/10.1080/03057260903142285>. Acesso em: 15 set. 2010.

LEVIN, D.M.; HAMMER, D.; COFFEY, J.E. Novice teachers' attention to student thinking. Journal of Teacher Education, Washington, v.60, n.2, p.142-55, 2009. Disponível em: <http:/find.galegroup.com/gtx/infomark. do? \&contentSet=IAC-Documents\&type=retrieve\&tabID=T002\&prodId=AONE\&docId=A195261845\&source=gale \&srcprod=AONE\&userGroupName=ucs\&version=1.0>. Acesso em: 20 ago. 2010.

LIMA, S.M.; REALI, A.M. O papel da formação básica na aprendizagem profissional da docência (aprende-se a ensinar no curso de formação básica?). In: MIZUKAMI, M.G.; REALI, A.M. (Orgs.). Formação de professores, práticas pedagógicas e escola. São Carlos: EdUFSCar, 2002. p.217-36.

MARCELO, C. Pesquisa sobre a formação de professores: o conhecimento sobre aprender a ensinar. Revista Brasileira de Educação, Rio de Janeiro, n.9, p.51-75, 1998. Disponível em: <http://www.anped.org.br/rbe/rbedigital/RBDE09/ RBDE09_06_CARLOS_MARCELO.pdf>. Acesso em: 18 ago. 2009.

MARCON, D. Construção do conhecimento pedagógico do conteúdo dos futuros professores de educação física. 2011. 574 f. Tese (Doutorado em Ciências do Desporto) - Faculdade de Desporto, Universidade do Porto, Porto, 2011. Disponível em: <http://repositorio-aberto.up.pt/bitstream/10216/55556/2/DISSERTA\%c3\%83O\% 202.pdf>. Acesso em: 24 jun. 2011.

MARCON, D.; GRAÇA, A.; NASCIMENTO, J.V. Estruturantes da base de conhecimentos para o ensino de estudantesprofessores de Educação Física. Motriz: Revista da Educação Física, Rio Claro, v.16, n.3, p.776-87, 2010. Disponível em: <http://www.periodicos.rc.biblioteca.unesp.br/index.php/motriz/article/view/3475/3216>. Acesso em: 25 ago. 2010. MARKS, R. When should teachers learn pedagogical content knowledge? In: ANNUAL MEETING OF THE AMERICAN EDUCATIONAL RESEARCH ASSOCIATION, 1991, Chicago. Proceedings... Chicago: AERA, 1991.

MARQUES, A.M. Formação do profissional da educação. 3. ed. Ijuí: Unijuí, 2000.

MEIRIEU, P. A pedagogia entre o dizer e o fazer: a coragem de começar. Porto Alegre: Artmed, 2002.

MENCK, P. Didactics as construction of content. Journal of Curriculum Studies, Glasgow, v.27, n.4, p.353-71, 1995. MESQUITA, I.; GRAÇA, A. A perspectiva construtivista da aprendizagem no ensino dos jogos desportivos. In: CONGRESSO DE EDUCAÇÃO FÍSICA E CIÊNCIAS DO DESPORTO DOS PAÍSES DE LÍNGUA PORTUGUESA: CULTURA E CONTEMPORANEIDADE NA EDUCAÇÃO FÍSICA E NO DESPORTO: E AGORA?, 9., 2002, São Luís. Anais... São Luís: Projeto Prata da Casa, 2002.

MESQUITA, I.; GRAÇA, A.; GOMES, A.R.; CRUZ, C. Examining the impact of a step game approach to teaching volleyball on student tactical decision making and skill execution during game play. Journal of Human Movement Studies, London, v.48, n.6, p.469-92, 2005.

METZLER, M.W.; TJEERDSMA, B.L.; MOZEN, D.M. Assessing pedagogical knowledge. Journal of Teaching in Physical Education, Champaign, v.19, n.4, p.487-507, 2000.

MIZUKAMI, M.G. Aprendizagem da docência: algumas contribuições de L. S. Shulman. Revista Educação, Santa Maria, v.29, n.2, p.1-11, 2004. Disponível em: <http://coralx.ufsm.br/revce/revce/2004/02/a3.htm>. Acesso em: 17 ago. 2009. MORINE-DERSHIMER, G.; KENT, T. The complex nature and sources of teachers' pedagogical knowledge. In: GESS-NEWSOME, J.; LEDERMAN, N.G. (OrgS.). Examining pedagogical content knowledge. Boston: Kluwer Academic, 1999. p.21-50.

O'SULLIVAN, M.; DOUTIS, P. Research on expertise: guideposts for expertise and teacher education in physical education. Quest, Champaign, v.46, n.2, p.176-85, 1994.

PARK, S.; JANG, J.-Y.; CHEN, Y.-C.; JUNG, J. Is pedagogical content knowledge (PCK) necessary for reformed science teaching?: evidence from an empirical study. Research in Science Education, Sidney, v.40, n.1, p.1-16, 2010. Disponível em: <http://www.springerlink.com.w10152.dotlib.com.br/content/q2wl21021736558r/>. Acesso em: 19 ago. 2010.

PARK, S.; OLIVER, J.S. Revisiting the conceptualisation of pedagogical content knowledge (PCK): PCK as a conceptual tool to understand teachers as professionals. Research in Science Education, Sidney, v.38, n.3, p.261-84, 2008. Disponível em: <http://dx.doi.org/10.1007/s11165-007-9049-6>. Acesso em: 1 out. 2009.

Rev. bras. Educ. Fís. Esporte, São Paulo, v.25, n.2, p.323-39, abr./jun. 2011 • 337 
PEREIRA, F; MESQUITA, I.; GRAÇA, A. A investigação sobre a eficácia pedagógica no ensino do desporto. Revista da Educação Física/UEM, Maringá, v.21, n.1, p.147-60, 2010. Disponível em: <http://periodicos.uem.br/ojs/index.php/ RevEducFis/article/view/6914/5716>. Acesso em: 20 jul. 2010.

PIMENTA, S.G. O estágio na formação de professores. 5. ed. São Paulo: Cortez, 2002.

RAMOS, V.; GRAÇA, A.; NASCIMENTO, J.V. O conhecimento pedagógico do conteúdo de treinadores de basquetebol: uma proposta de investigação qualitativa com treinadores experientes. In: CONGRESSO INTERNACIONAL DE JOGOS DESPORTIVOS: OLHARES E CONTEXTOS DA PERFORMANCE - DA INICIAÇĀO AO ALTO RENDIMENTO, 1., 2007, Porto. Anais... Porto: Faculdade de Desporto/Universidade do Porto, 2007.

O conhecimento pedagógico do conteúdo: estrutura e implicações à formação em Educação Física. Revista

Brasileira de Educação Física e Esporte, São Paulo, v.22, n.2, p.161-71, 2008. Disponível em: <http://www.usp.br/eef/ rbefe/v22n22008/7_RBEFE_v22_n2_2008_p161_64.pdf / http://www.usp.br/eef/rbefe/v22n22008/7_RBEFE_v22_ n2_2008_p165_71.pdf>. Acesso em: 6 out. 2009.

RINK, J.E. Teacher education programs: the role of context in learning how to teach. The Journal of Physical Education, Recreation \& Dance, Reston, v.68, n.1, p.17-24, 1997.

RIOS, T.A. Competência ou competências: o novo e o original na formação de professores. In: ROSA, D.E.G.; SOUZA, V.C. (Orgs.). Didática e práticas pedagógicas: Interfaces com diferentes saberes e lugares formativos. Rio de Janeiro: DP\&A, 2002. p.154-72.

ROVEGNO, I. Learning and instruction in social, cultural environments: promising research agendas. Quest, Champaign, v.60, n.1, p.84-104, 2008.

Situated perspectives on learning. In: KIRK, D.; MacDONALD, D.; O’SULLIVAN, M. (Orgs.). The handbook of physical education. London: Sage, 2006. p.262-74.

. Teaching within a curricular zone of safety: school culture and the situated nature of student teachers' pedagogical content knowledge. Research Quarterly for Exercise and Sport, Washington, v.65, n.3, p.269-79, 1994.

Theoretical perspectives on knowledge and learning and a student teacher's pedagogical knowledge of dividing and sequencing subject matter. Journal of Teaching in Physical Education, Champaing, v.14, p.284-304, 1995.

ROVEGNO, I.; DOLLY, J.P. Constructivist perspectives on learning. In: KIRK, D.; MacDONALD, D.; O’SULLIVAN, M. (Orgs.). The handbook of physical education. London: Sage, 2006. p.242-61.

SCHEMPP, P.; MANROSS, D.; TAN, S.; FINCHER, M. Subject expertise and teachers' knowledge. Journal of Teaching in Physical Education, Champaign, v.17, n.3, p.342-56, 1998.

SCHINCARIOL, L.M. The types, sources, and perceived relevance of knowledge acquisition, and the enacted effects when teaching unfamiliar and familiar physical education content. 2002. 287 f. (Doctoral thesis) - Department of Philosophy, The Ohio State University, Columbus, 2002. Disponível em: <http://proquest.umi.com/pqdweb?did=7652 $51041 \&$ sid=5\&Fmt=2\&clientId=37541\&RQT=309\&VName=PQD>. Acesso em: 25 mar. 2008.

SEEL, H. "Allgemeine Didaktik" ("General Didactics") and "Fachdidaktik" (“Subject Didactics"). TNTEE Publications Volume, [S.1.], v.2, n.1, p.13-20, 1999.

SEGALL, A. Revisiting pedagogical content knowledge: the pedagogy of content/the content of pedagogy. Teaching and Teacher Education, Oxford, v.20, n.5, p.489-504, 2004.

SHULMAN, L.S. Knowledge and teaching: foundations of the new reform. Harvard Educational Review, Cambridge, v. 57, n.1, p.1-27, 1987.

$14,1986$.

Those who understand: knowledge growth in teaching. Educational Researcher, Washington, v.15, n.2, p.4-

SIEDENTOP, D. Content knowledge for physical education. Journal of Teaching in Physical Education, Champaign, v.21, n.4, p.368-77, 2002a.

Ecological perspectives in teaching research. Journal of Teaching in Physical Education, Champaign, v.21, n.4, p.427-40, July, 2002b.

SILVA, M.L.R. Aplicação dos saberes na sala de aula: desafios para o professor. Notandum, Porto, v.11, n.16, p.46-52, 2008. Disponível em: <http://www.hottopos.com/notand16/malu.pdf>. Acesso em: 11 set. 2009.

SMITH, R. "Before teaching this I'd do a lot of reading" preparing primary student teachers to teach science. Research in Science Education, Sidney, v.27, n.1, p.141-54, 1997. Disponível em: <http://dx.doi.org/10.1007/BF02463038>. Acesso em: 19 ago. 2010.

SOUZA, A.; OSLIN, J. A player-centered approach to coaching. The Journal of Physical Education, Recreation \& Dance, Reston, v.79, n.6, p.24-30, 2008. 
TARDIF, M.; RAYMOND, D. Saberes, tempo e aprendizagem do trabalho no magistério. Educação \& Sociedade, Campinas, v.21, n.73, p.209-44, 2000. Disponível em: <http://www.scielo.br/scielo.php?script=sci_arttext\&pid=S0101$73302000000400013 \& \operatorname{lng}=$ pt\&nrm=iso $>$. Acesso em: 11 set. 2009.

TINNING, R. Engaging Siedentopian perspectives on content knowledge for physical eEducation. Journal of Teaching in Physical Education, Champaign, v.21, n.4, p.378-91, 2002.

VAN DRIEL, J.; VERLOOP, N.; DE VOS, W. Developing science teachers' pedagogical content knowledge. Journal of Research in Science Teaching, New York, v.35, n.6, p.673-95, 1998.

VEAL, W.R.; MAKINSTER, J.G. Pedagogical content knowledge taxonomies. Electronic Journal of Science Education, Reno, v.3, n.4, p.1-16, 1999. Disponível em: <http://wolfweb.unr.edu/homepage/crowther/ejse/vealmak.html>. Acesso em: 22 out. 2009.

WHIPPLE, C.E. Preservice teachers' views of content and pedagogical knowledge presented in the elementary component of a physical education teacher education program. 2002. $341 \mathrm{f}$. (Doctoral thesis) - Department of Philosophy, The Ohio State University, Columbus, 2002. Disponível em: <http://proquest.umi.com/pqdweb?did=764690441\&sid= $4 \& \mathrm{Fmt}=2 \&$ clientId=37541\&RQT=309\&VName=PQD>. Acesso em: 10 set. 2009.

WOODS, M.; GOC KARP, G.; ESCAMILLA, E. Preservice teachers learning about students and the teaching-learning process. Journal of Teaching in Physical Education, Champaign, v.20, n.1, p.15-39, 2000.

ZEICHNER, K.M. A formação reflexiva de professores: ideias e práticas. Lisboa: EDUCA, 1993.

. Rethinking the connections between campus courses and field experiences in college-and university-based tea-

cher education. Journal of Teacher Education, Washington, v.61, n.1-2, p.89-100, 2010. Disponível em: <http://find. galegroup.com/gtx/infomark.do?\&contentSet=IAC-Documents\&type=retrieve\&tabID=T002\&prodId=AONE\&docId= A216896342\&source=gale\&srcprod=AONE\&userGroupName=ucs\&version=1.0>. Acesso em: 20 ago. 2010.

\begin{tabular}{r|r} 
ENDEREço \\
Daniel Marcon \\
Curso de Educação Física & \\
Universidade de Caxias do Sul & Recebido para publicação: 09/02/2011 \\
R. Francisco Getúlio Vargas, 1130 & Revisado: 04/05/2011 \\
95070-560 - Caxias do Sul - RS - BRASIL & Aceito: 30/05/2011 \\
e-mail: dmarcon@ucs.br & \\
&
\end{tabular}

